\title{
Menos pode ser mais: do decrescimento e descomplexificação à complexidade
}

DOI 10.26512/lc.v24i0.19699

\author{
José Eduardo García Díaz \\ Universidad de Sevilla/ Red IRES/ Asociación Montequinto Ecológico-Ecologistas \\ en Acción; jeduardo@us.es
}

Giselle Watanabe Universidade Federal do ABC/ Centro de Ciências Naturais e Humanas; giselle.watanabe@ufabc.edu.br

\section{Resumo}

Nos últimos tempos há um discurso reducionista que vem ganhando espaço em diversas publicações, conferências e debates amplos sobre o decrescimento e colapso associado aos limites biofísicos do meio que, por sua vez, levariam ao esgotamento de recursos naturais e às mudanças climáticas. Nessas abordagens é comum a defesa de que o decrescimento supõe uma descomplexificação desejada e/ou inevitável do sistema social. Esses pressupostos podem disseminar uma ideia equivocada sobre a forma de lidar com as questões socioambientais ao mesmo tempo em que aponta para limitações estruturais do ponto de vista social. Diante dessa problemática iminente, neste ensaio discutem-se alguns aspectos da perspectiva da complexidade partindo do pressuposto de que ela nos ajuda a compreender que o decrescimento não significa inevitavelmente uma diminuição da complexidade do sistema social. E nos mostra como uma formação mais criativa e crítica demandará intervenções que levem a uma proposta menos linear, pautada em uma mudança de paradigma e na própria forma de se relacionar socialmente.

Palavras-Chave: complexidade; decrescimento; crítico; educação; ambiente. 


\section{Abstract}

In recent times there has been a reductionist discourse that has been gaining ground in a number of publications, conferences and broad debates on the decline and collapse associated with the biophysical boundaries of the environment, which in turn would lead to the depletion of natural resources and climate change. In these approaches it is common to defend that the decrease presupposes a desired and / or inevitable decomplexification of the social system. These assumptions can disseminate a misconception about how to deal with socio-environmental issues while at the same time pointing to structural limitations from a social point of view. Faced with this imminent problem, this essay discusses some aspects of the perspective of complexity based on the assumption that it helps us to understand that the decline does not inevitably mean a decrease in the complexity of the social system. And it shows us how a more creative and critical formation will require interventions that lead to a less linear proposal, based on a paradigm shift and on the way to socially relate.

Keywords: complexity; decrease; critical; education; environment.

\section{Resumen}

En los últimos tiempos hay un discurso reduccionista asumido en diversas publicaciones, conferencias y debates sobre el decrecimiento y colapso asociado a los límites biofísicos del medio que, a su vez, llevarían al agotamiento de recursos naturales y cambio climático. En estos enfoques se observa la defensa de que el decrecimiento supone una descomplejización deseada y/o inevitable del sistema social. Estos supuestos pueden diseminar una vista equivocada sobre la forma de tratar con las cuestiones socioambientales al mismo tiempo que apunta para las limitaciones estructurales desde el punto de vista social. Ante esta problemática inminente, en este ensayo se discuten algunos aspectos de la perspectiva de la complejidad suponiendo que eso nos ayuda a comprender que el decrecimiento no significa inevitablemente una disminución de la complejidad del sistema social. Y nos muestra cómo una formación más creativa y crítica demandará intervenciones que lleven a una propuesta menos directiva, guiada por un cambio de paradigma y por la propia manera de relacionarse socialmente.

Palabras clave: complejidad; decrecimiento; crítico; la educación; medio ambiente. 


\section{Resumé}

Ces derniers temps, il y a un discours réductionniste qui a gagné du terrain dans plusieurs publications, des conférences et des discussions approfondies sur la diminution et l'effondrement associé aux limites biophysiques de l'environnement qui, à son tour, conduirait à l'épuisement des ressources naturelles et le changement climatique. Dans ces approches, il est courant de défendre que la diminution présuppose une décomplexification désirée et / ou inévitable du système social. Ces hypothèses peuvent disséminer une idée fausse sur la façon de traiter les problèmes socio-environnementaux tout en soulignant les limites structurelles d'un point de vue social. Face à ce problème imminent, cet article aborde certains aspects de la perspective de la complexité en partant du principe que cela nous aide à comprendre que le déclin ne signifie pas forcément une diminution de la complexité du système social. Et cela nous montre comment une formation plus créative et critique nécessitera des interventions qui mèneront à une proposition moins linéaire, fondée sur un changement de paradigme et sur le chemin de la relation sociale.

Mots-clés: complexité; diminuer; critique l'éducation; environnement.

\section{AS QUESTÕES SOCIOAMBIENTAIS E O "CONSENSO" SOBRE A DESCOMPLEXIFICAÇÃOO}

As questões socioambientais vêm ganhando espaços em diversas agendas tais como a política, econômica, cultural e educacional. Especialmente, no contexto das políticas públicas para a educação, há uma gama considerável de documentos que dão indicativos para a promoção de uma Educação Ambiental mais crítica no contexto do ensino básico. No Brasil, exemplo disso ocorre na Política Nacional de Educação Ambiental (PNEA) (Brasil, 1999); nos Parâmetros Curriculares Nacionais (PCN) para os ensinos Fundamental e Médio (Brasil, 2000); e Orientações Educacionais Complementares ( $\mathrm{PCN}+$ ) (Brasil, 2002). Na Espanha, essas proposições comparecem, por exemplo, na Ley Orgánica 2/2006 de Educación (LOE); Ley Orgánica 8/2013 para melhoria da qualidade educativa (LOMCE); e Ordem de 10 de agosto de 2007 que trata do currículo mínimo da Educação Primária de Andaluzia (Puig-Gutiérrez et al., 2017). Essa preocupação também é evidenciada em reflexões presentes nos congressos e publicações da área de ensino e educação nos dois países, tal como apresentado por Watanabe e Rodríguez-Marín (2018) ao identificar as aproximações dos trabalhos socioambientais com aspectos da complexidade presentes na formação de professores, ideias de aluno, educadores e/ou mídia, proposição de atividades e 
práticas educativas, planejamento e currículo e reflexões teóricas.

Ainda que seja possível encontrar proposições preocupadas com mudanças na forma de pensar e agir tanto nos contextos escolar e social que conduza a uma perspectiva de mundo mais crítica e complexa (Carvalho, Watanabe \& Rodrigues-Marin, 2017; Watanabe \& Kawamura, 2017; Watanabe \& Carvalho, 2016); de forma geral, notase que grande parte do pensamento atual sobre a questão socioambiental aponta para uma crise sistêmica associada ao início de um processo de decrescimento que pode levar a um colapso da civilização (Fernández \& González, 2014; Casal, 2016; Prats, Herrero \& Torrego, 2016; Taibo, 2016). Simplificando muito o assunto, a ideia de decrescimento aponta para ao menos duas concepções não excludentes. A primeira delas salienta que o decrescimento deve ser um objetivo social desejável para resolver os problemas graves decorrentes da crise; e enfatiza que ele é uma opção social associada à conscientização dos cidadãos e das cidadãs frente à necessidade de mudar nossa ética e estilo de vida. A segunda concepção indica que o decrescimento é um evento inevitável causado pelo choque de nossa civilização com seus limites biofísicos e, nesse caso, nos cabe preparar a população (aumentando sua resiliência) para que o colapso não seja caótico, mas ordenado e justo (Fernández \& González, 2014; Casal, 2016; Pratz, Herrero \& Torrego, 2016; Taibo, 2016; Turiel, 2016).

A ideia de decrescimento e colapso acompanha frequentemente a ideia de descomplexificação social, entendida como um valor a ser desenvolvido (concepção próxima ao trabalho de Latouche, 2007, 2009 e 2012) e como algo necessário e inevitável (Fernández \& González, 2014; Casal, 2016; Riechmann, 2016; Taibo, 2016). Descomplexificar, desse ponto de vista, implica em uma menor produção de bens (diminuição do Produto Interno Bruto - PIB) e menor consumo, menos habitantes, menor grau de especialização profissional, desorganização de estruturas hierárquicas, menos "conectividade" e menos transporte de materiais, menos ciência e menos tecnologia etc. Conforme indicado por Taibo (2016), cinco verbos resumem a possível mudança associada ao choque com nossos limites biofísicos: decrescer, desurbanizar, destecnologizar, despatriacar e descomplexificar.

De certo, a sociedade contemporânea caminha para um mundo com menor disponibilidade de energia fácil, recursos mais restritos e ecossistemas transformados pelas mudanças climáticas. E isso levará a uma dificuldade em manter a atual organização social que, por sua vez, aponta para um colapso da civilização industrial. Por outro lado, essa condição não implica que o decrescimento sempre determina uma descomplexificação. E é esse ponto que cabe promover uma reflexão mais profunda e detida. Essa reflexão até pode parecer um debate estritamente acadêmico, mas não o é! Especialmente porque ao assumir certos princípios sem críticas, em um momento de transição, podemos alcançar diagnósticos inadequados e promover práticas desajustadas e pouco adaptativas. Além disso, a insistência do discurso ecologista em termos como colapso, declínio, degradação, simplificação ou regressão social, 
pode produzir muita confusão e rejeição social discriminada se o significado desses termos não forem adequadamente esclarecido.

A partir dessas preocupações, esse ensaio, ao pretender fomentar um debate sobre a descomplexificação e complexificação, aborda o conceito de sistemas complexos, o debate atual sobre a eficiência energética e a necessidade de complexificar o conhecimento. Por fim, trata de uma educação em e para o decrescimento que de antemão aponta para aspectos da criticidade e complexidade.

\section{A LAGARTA, A BORBOLETA E O PIB: MAIS OU MENOS COMPLEXO?}

Pensemos que o sistema capitalista é como uma grande lagarta que se alimenta e cresce sem limites. Consideremos que antes de morrer, pelo esgotamento do alimento disponível, ela se transforma em uma borboleta. Do ponto de vista da complexidade podemos classificá-las, tanto a lagarta quanto a borboleta como sistemas complexos. Mas o que é mais complexo? A resposta dependerá das variáveis usadas para definir um sistema como mais ou menos complexo. Se atribuirmos relevância às variáveis quantitativas do tipo "peso" ou "equilíbrio calórico", a lagarta será mais complexa do que a borboleta. Mas se analisarmos as variáveis qualitativas, como a capacidade de se reproduzir, a borboleta torna-se um sistema mais complexo. Desse ponto de vista, o conceito de complexidade é muito relativo.

Se analisarmos o contexto social/político/econômico sob perspectiva semelhante, nos parece inviável utilizar parâmetros como o PIB ou o número de habitantes (parâmetros quantitativos) para tratar e comparar à forma de organização social (parâmetros qualitativos). Toma-se aqui a forma de organização social a partir do tipo de interação presente considerando, por exemplo, que as relações antagônicas não são as mesmas que as de complementaridade; ou que haja o predomínio de estruturas hierárquicas ou estruturas que privilegiem as redes horizontais. Da mesma forma, não é possível falar sobre a complexidade do conhecimento com indicadores pautados no acúmulo de dados ou quantidade de graduados, considerando o conhecimento em relação ao formato organizacional dos sistemas de ideias. Qual é o problema disso tudo? Ele reside numa tentativa de converter uma certa perspectiva da complexidade dos sistemas em um axioma que ignora a existência de outras perspectivas, o que leva a um empobrecimento do debate sobre as possíveis transições em uma situação de decrescimento. Acima de tudo, esse tipo de visão (Tainter, 1996) em que predomina na literatura ecológica fomenta uma concepção de complexidade muito restrita.

O paradigma complexidade discutido por Morin (1986, 1987, 1988, 1992, 1994), Prigogine (1988, 1993, 1996, 2002, 2009) e Prigogine e Stengers $(1984,1992)$ 
descreve as mudanças dos sistemas abertos complexos em reorganização contínua (no caso, o eco-sócio-sistemas). Para Morin, essa reorganização contínua refere-se a uma transformação em que intervêm três fatores interagentes: matéria, energia e informação. $\mathrm{Na}$ interação entre eles nenhum fator é predominante, de modo que a mudança pode ser explicada por uma causalidade complexa (loops, recursão, autoorganização e reorganizações) e não por relações causais lineares entre esses três fatores.

Aspectos da complexidade de sistemas, considerando o conceito de decrescimento, nos levam a refletir sobre alguns axiomas e suas interpretações que, de antemão, parecem discutíveis. Um deles refere-se à ideia de que em uma situação de decrescimento há menos recursos energéticos e materiais. Essa condição não deve nos levar a superestimar as dimensões da matéria e energia sobre a dimensão da informação (entendida aqui como uma organização); e nem estabelecer relações de causalidade lineares. A este respeito, pode-se observar a abordagem determinista e reducionista ao tratar do colapso civilizatório, especificamente, ao condicionar a complexidade de uma sociedade à quantidade de energia disponível (Fernández \& González, 2014; Casal, 2016). Em particular, Casal (2016), ao tratar dos 12 axiomas que sustentam a ideia de colapso civilizatório (premissas que compartilhamos em grande parte), salienta no axioma 4 que:

A complexidade de uma sociedade (ou de um modelo de civilização) depende dos fluxos de energia que dispõe: se há mais energia é possível criar sociedade mais complexas (...) (Casal, 2016, p. 36). Os níveis de complexidade do atual modelo de civilização, que denominamos industrial, não podem se manter (Casal, 2016, p. 37).

O decrescimento é inevitável, há que se partir desta premissa básica: se há menos energia disponível, não existe crescimento possível e as economias se contraem, quando não colapsam até níveis mais baixos de complexidade estrutural (segundo Tainter) (Casal, 2016, p. 217) ${ }^{1}$.

A partir dessas ideias parece clara a correlação entre energia e crescimento: se tivermos menos energia menor será o crescimento. No entanto, do nosso ponto de vista, a premissa não deveria ser direta: Será que menor crescimento significa menos complexidade? Por que associar a complexidade apenas ao crescimento, uma variável quantitativa? O declínio da complexidade afetaria igualmente os diferentes subsistemas (a burocracia estatal e uma cooperativa local são subsistemas muito distintos)? Uma organização da produção de bens de acordo com os critérios da economia bem comum (Felber, 2015) é menos complexa do que uma economia orientada de acordo com critérios convencionais, como o PIB? Por fim, algum incremento na complexidade é um passo em direção a um declínio no futuro? (Esse é um axioma muito difundido nos contextos socioambiental, da educação e do ensino).

1 Tradução nossa. 
O argumento central de Tainter (1996) para justificar sua tese é de que a mudança de complexidade nas sociedades desenvolve-se de acordo com uma curva de Gauss (Curva de Sino ou Gaussiana), de modo que, inevitavelmente, um aumento de complexidade implica em um decrescimento da mesma (Lei dos Rendimentos Decrescentes, Lei das Proporções Variáveis ou Lei da Produtividade Marginal Decrescente). O sistema torna-se progressivamente mais complexo (e ganha em eficiência), mas chega um momento em que sua própria complexidade leva a ineficiência e decadência. Tal como aponta Fernández e González (2014), há muitos dados que indicam que a lei dos rendimentos decrescentes pode ser vista na evolução das sociedades dominantes. Mas essa é uma lei universal aplicável a outros modelos sociais? Aqui está um problema de atribuição causal porque a causa é "complexidade" ou há outros fatores envolvidos (então devemos falar mais sobre correlação do que causalidade)?

Do nosso ponto de vista, parece claro que Tainter (1996) ignora fatores chave que explicam a evolução das instituições sociais: elas não são neutras, podendo estar a serviço do bem comum de toda a sociedade (e servir para resolver problemas socioambientais) ou responder aos interesses de grupos sociais específicos que detêm o poder no momento atual; e podem ser regidas por critérios de antagonismo ou critérios de complementaridade e solidariedade. Esses fatores são determinantes quando se trata de entender esse declínio "inevitável". Nesse sentido, os mecanismos de controle e autoperpetuação do sistema capitalista (a exemplo também do Império Romano ou de outras sociedades baseadas em dominação e exploração) não estão falhando porque atingiram um "teto" de complexidade institucional, mas porque as contradições internas dos sistemas tornam isso possível. Quando Tainter (1996) dá exemplos da crescente complexidade burocrática e dos mecanismos de segurança e controle que levam ao colapso, não nos diz algo fundamental: que essa burocracia e esses mecanismos não estão lá para resolver o problema de ajustar a atividade humana à ecologia planetária, mas para autoperpetuar o domínio de algumas classes sociais.

Além disso, a afirmação de Tainter (1996) de que as sociedades buscam soluções mais práticas e racionais para os problemas (a exemplo do Império Romano) também aponta que tais soluções são discutíveis visto que não impedem a decadência do sistema. Ou seja, propõe-se que as organizações sociais sejam criadas para resolver problemas, mas quando tornam-se excessivamente complexas, deixam de ser eficientes para a referida função. Nesta afirmação, há uma questão chave que deve ser considerada. Ela se refere a quais problemas estavam sendo resolvidos: os problemas relacionados ao bem comum de toda a população ou os problemas de auto-perpetuação da classe dominante? Isso é relevante visto que não é o mesmo empreender um caminho para a solução de problemas em uma sociedade baseada no antagonismo e dominação do que em uma sociedade baseada na complementaridade.

Em última análise, a aplicação da lei dos rendimentos decrescentes como axioma universal supõe duvidar da possibilidade de organizações sociais com uma maior 
eficiência energética, capazes de manter um certo grau de complexidade em uma situação de decrescimento, um tema de grande importância para o qual dedicaremos uma seção deste texto.

Também seria importante esclarecer e relativizar outra ideia: a hierarquização social e o aumento do trabalho especializado enquanto indicadores de complexidade. Considera-se que uma estrutura hierárquica e piramidal com muitos "nichos profissionais" é uma estrutura muito complexa, ao invés de um conjunto de redes horizontais interconectadas e autossuficientes. Ou seja, a estratificação e a desigualdade social são ditas "complexas". Mas essa concepção entra em conflito com um conceito originado na Biologia: a neotenia dos mamíferos, que se refere à propriedade de retenção/manutenção das características dos indivíduos imaturos ao longo de seu desenvolvimento, conferindo-Ihes a plasticidade de adaptação ao meio ambiente. Este princípio é essencial nos seres humanos visto que somos organismos generalistas e polivalentes, e essa é uma característica básica de nossa espécie. Nossa curiosidade inata, tendência para explorar e investigar, e a capacidade de usar recursos muito diversos são características de complexidade. Então, por que considerar que hierarquização e hiperespecialização (e a consequente submissão e falta de autonomia), e não a polivalência das pessoas, são indicadores de complexidade? Não estamos simplesmente assumindo os valores do sistema dominante ao decidir o que é e o que não é complexo?

Do mesmo modo, é importante relativizar a ideia de que, com a conectividade, a lei dos rendimentos decrescentes também é contemplada. Argumenta-se que, embora inicialmente as redes sejam boas do ponto de vista da maior eficiência, há um momento em que as repercussões das falhas são facilmente susceptíveis a propagação (se houver muita dependência entre os nós da rede), de modo que quanto mais interrelacionados estão as redes maior será a tendência para transmitir os problemas. Portanto, mais complexidade pode significar também mais vulnerabilidade. A chave é, novamente, tratar a complexidade como quantidade e não como qualidade (por exemplo, a autonomia de cada nó da rede, o tipo de interações que ocorrem entre elas, os interesses que regulam a troca etc.). Não é uma lei universal que um aumento na complexidade na conectividade supõe inevitavelmente uma diminuição subsequente. O exemplo mais claro é o dos sistemas de ideias: como aponta Morin (1992, 2001), uma complexificação progressiva dos sistemas de ideias tem um efeito multiplicador e jamais de subtração. Hoje em dia, a ciberconectividade supõe um grande desperdício de energia, mas isso não se deve à "complexidade" do sistema e sim aos conteúdos que levam ao maior controle sobre os interesses e valores da população. O grau de conectividade será mais ou menos resiliente não porque existam redes mais ou menos "complexas", mas em função do tipo de redes que organizamos (a este respeito, todos os exemplos referem-se aos distúrbios amplificados na rede, voltados à lógica organizacional do sistema capitalista: uma crise financeira, um atentado terrorista, um ataque cibernético etc.). 
Além disso, uma sociedade em rede não precisa ter a lógica de um organismo pluricelular (que no geral é tomada como referência). No organismo, o intervalo de estabilidade é muito curto visto que seu estado não pode estar longe de um ótimo pré-estabelecido. Em vez disso, teríamos que considerar uma lógica organizacional ecossistêmica, muito mais aberta, na qual os processos de reorganização são mais relevantes do que os de auto-organização (Morin, 1986; 1987). Como indica esse autor, o relevante é o fator qualitativo: o que define uma rede melhor é o tipo de interações que a organiza.

Em suma, não parece conveniente considerar a lei dos rendimentos decrescentes como um axioma universal. Obviamente, ela nos ajuda a entender a evolução da burocracia administrativa, mas não serve para explicar, por exemplo, a evolução de uma horta em permacultura ou as mudanças na organização de um sistema de ideias (aspectos que trataremos adiante).

Por fim, é fundamental discutir algumas questões que se referem às interações entre matéria, energia e organização, a saber: $O$ axioma central "menos energia é menos complexidade" se sustenta do ponto de vista da Termodinâmica e da Ecologia? Que tipos de organizações sociais são viáveis dentro dos limites biofísicos? Qual dessas organizações pode ser considerada mais ou menos complexa frente a atual sociedade industrial?

Os Princípios da Termodinâmica nos diz que a energia não é criada nem destruída, apenas se transforma, e nessa transformação se degrada levando ao aumento da entropia no sistema. Por conseguinte, se tivermos cada vez menos energia de qualidade disponível (conceito de negentropia) inevitavelmente teremos uma simplificação da organização social. Mas se não queremos ser deterministas e tampouco reducionistas, temos que reconhecer que, assim como as a energia de qualidade disponível condiciona a organização social, tal organização também condiciona o uso dessa energia. Em outras palavras, seria possível incluir um maior grau de complexidade (não entendido como crescimento) com menos energia, se essa fosse usada de forma mais eficiente. Nesta perspectiva, a chave é tanto a organização quanto os recursos, visto que os recursos não são o único motor evolutivo (se não quisermos cair em uma posição reducionista).

Determinados sistemas complexos (como os eco-sócio-sistemas) submetidos a um fluxo de energia apresentam uma qualidade interessante: embora a energia se degrade, ela deixa uma "pegada" (impressão ou marca) em forma de informação (organização, nos termos de Morin). Ou seja, o sistema se ordena de tal forma que, embora a energia flua (perdendo "qualidade"), ainda há estruturas que condicionarão o uso posterior desse fluxo de energia. Como Margalef (1980) salienta:

O acúmulo de informação não é gratuito, pois significa trocas de energia e, portanto, um aumento do valor da função entropia. Mas a informação conseguida, persistente em 
forma de estrutura, pode orientar em um ou outro sentido o uso da energia no futuro, de maneira tal que se pode julgar mais eficiente (Margalef, 1980, p. 21)².

Esta perspectiva corresponde a uma mudança essencial que ocorre na Ecologia do século passado, a saber: a transição da concepção da biosfera como um conjunto de relações causais lineares (mecanicismo) nas quais os recursos determinam a organização da vida em direção a uma concepção interativa, em que a organização viva também influencia o biótipo (Levins e Lewontin, 1980; Margalef, 1980; Mcintosh, 1985; Morin, 1987; Golley, 1993). Margalef (1974) destaca que na década dos anos setenta (momento culminante da revolução conceitual da Ecologia) o ecossistema passou a ser visto como um sistema de elementos vivos e não vivos envolvidos em um processo dinâmico e incessante de interação, ajuste e regulação que supõe a evolução ao nível das espécies e à sucessão ecológica de todo o sistema.

Deléage (1993) aponta para a necessidade de evitar os "reducionismos termodinâmicos" ao tratar de sistemas tais como as sociedades humanas e os ecossistemas. Isso porque não é possível explicar a complexidade desses sistemas apenas do ponto de vista de um equilíbrio de calorias ${ }^{3}$, pois se tratam de sistemas abertos em reorganização contínua que, sem um ótimo pré-estabelecido (caso dos organismos) e como entidades históricas, usaram o fluxo de energia para se organizar, acumulando informação sob a forma de programas genéticos e culturais. Referem-se a uma organização que, ao mesmo tempo, condiciona a circulação de materiais e o fluxo de energia em nosso planeta.

A partir dessas considerações não faz sentido falar da curva de Gauss, de mudanças periódicas e de ciclos sociais. A concepção de colapsos civilizatórios associados aos ciclos históricos (tão presentes na literatura ambiental e usada como base nos postulados de Tainter) não são convincentes. Um modelo de mudança baseado em ciclos e espirais não explica adequadamente a evolução de sistemas que estão em contínua reorganização (Morin, 1986; 1987). Parece mais apropriado considerar os modelos propostos pela Ecologia e pela perspectiva da complexidade para entender a evolução da biosfera. Margalef (1974, p.738), ao tratar da evolução dos ecossistemas, considera a mudança helicoidal, com um componente "cíclico" e outro, mais determinante, irreversível, de caráter evolutivo (a "seta do tempo").

Nessa perspectiva, Prigogine (1996) ao tratar dos sistemas irreversíveis e da seta do tempo considera a dissipação e sistemas longe do equilíbrio. Especialmente, no que se referem aos sistemas vivos, Prigogine e Stengers (1984) apontam que a sua evolução pode levar ao ponto de bifurcação, no qual as simetrias preexistentes podem ser quebradas o que, por sua vez, provoca a quebra de comportamentos estáveis.

2 Tradução nossa.

3 De fato, o conceito de metabolismo, tão usado na literatura ecologista como metabolismo social, se origina e desenvolve na Biologia associada ao nível do organismo e não à escala eco-sócio-sistêmica. 
Isso conduz, por exemplo, à amplificação de alguns sinais que são essenciais para a dinâmica de reprodução, do ciclo-limite. Quando tratamos da vida há de ser ter claro que ela se mantém graças à batalha intensa entre a ordem e desordem do sistema, que implica numa relação equilibrada entre a entropia interna e externa. A questão da vida nesse contexto vai culminar na ideia de que o tempo e a complexidade desempenham um papel muito importante na evolução biológica e que, portanto, o $2^{\circ}$ Princípio da Termodinâmica vem no sentido de explicitar a criatividade, a criação (Watanabe, 2014). Segundo Prigogine e Stengers (1984),

(...) Em particular, no seio de um sistema que evolui globalmente para o equilíbrio - e nós podemos dizer, por exemplo, que é o caso do sistema planetário no seu conjunto -, os fluxos irreversíveis podem criar, de maneira previsível e reprodutível, a possibilidade de processos locais de auto-organização. Nesse contexto, um fenômeno como o aparecimento de formas vivas poderia ser considerado previsível do ponto de vista da teoria física. A vida escaparia certamente ao principio de ordem de Boltzmann, mas entraria na ordem das possibilidades implicadas pela termodinâmica longe do equilíbrio. (Prigongine \& Stengers, 1984, p.114).

Diante dessas ideias, parece contraditório considerar que "a história é uma sucessão cíclica, mas que os mesmos eventos não acontecem novamente na mesma ordem, de modo que cada nova etapa é única", tal como faz Fernández e González (2014). Em um modelo que considera a mudança cíclica faz sentido falar sobre crescimento e decrescimento da complexidade social. Neste caso, são consideradas apenas certas variáveis (número de pessoas, classes sociais, papéis sociais, quantidade de energia ou informação utilizada, número de agências e instituições, quantidade de conexões etc.), o que explicaria uma alteração helicoidal muito mais aberta e indeterminada (tal como a eficiência energética, predomínio da complementaridade em relação ao antagonismo, predomínio de atividades cooperativas e não competitivas, natureza das interações que criam organização etc.). Precisamente, o primeiro grupo de variáveis é o mais usado pelo pensamento dominante ao tratar do crescimento e progresso, portanto, é importante que possamos criticar seu uso.

Para nós, este debate parece relevante para interpretar o colapso e transição (em vez da revolução) para os sistemas pós-colapsados. Em especial se admitimos que: (a) com uma determinada fonte de energia um sistema pode fazer coisas muito diferentes de acordo com a informação (organização) desse sistema; e (b) os processos de mudança social não são cíclicos, mas evolutivos, o que significa que qualquer mudança deve ser interpretada considerando a transição para algo diferente e não ao retorno de situações precedentes.

Podemos concluir que, mesmo com menos energia, ainda seria possível manter um certo grau de complexidade em determinadas organizações sociais. A chave estaria na eficiência energética do sistema social. Ou seja, na capacidade de atingir certos objetivos com o menor consumo de energia. 


\section{O DEBATE DA EFICIÊNCIA ENERGÉTICA}

Ao tratar do decrescimento e colapso dos sistemas há um debate importante sobre o papel da eficiência energética na resolução de problemas socioambientais contemporâneos. Acima de tudo, a discussão volta-se à ideia de que a eficiência energética é um mito (Fernández \& González, 2014). Os dados mais utilizados para indicar o aumento da eficiência não apresenta uma solução para o problema. Tratase do paradoxo de Jevons (ou efeito bumerangue - rebound effect) ${ }^{4}$ que mostra que um aumento relativo da eficiência de uma tecnologia implica na diminuição da eficiência absoluta do conjunto do sistema. Esse efeito sugere que a melhora da eficiência energética das máquinas leva ao desperdício de energia e ao declínio do sistema. Turiel (2011) destaque que:

(...) sem modificar outros fatores resulta que se está dando um incentivo para consumir mais desse produto se seu maior consumo nos indica uma vantagem, já que com o mesmo rendimento disponível podemos consumir mais; pior ainda, quem antes não podia ter acesso a esse consumo por ter uma renda insuficiente agora poderá tê-lo (...) Entende-se, portanto, que o chamado para melhorar a eficiência é contraproducente se não for acompanhado por outras medidas, porque em vez de dar um estímulo para consumir menos, dá-se um estímulo para consumir mais. (Turiel, 2011)

A chave está nas frases "sem modificar outros fatores" e "se não for acompanhada por outras medidas". Ou seja, o paradoxo de Jevons se dá em uma organização social baseada em determinados valores (consumo como sinônimo de desperdício, neste caso), controlada de acordo com certos interesses de classe (obtendo o máximo benefício) e não é, portanto, um fenômeno universal e comum a qualquer modelo social. Portanto, compartilhando a perspectiva de um mundo futuro de baixa energia, parece aceitável a ideia de colapso inevitável por ineficiência energética porque, na realidade, no atual sistema, a maior parte da energia disponível é desperdiçada porque faz sentido econômico fazê-lo (Turiel, 2017). A este respeito, é importante discutir o papel da eficiência energética na transição pós-capitalista.

O posicionamento dominante na literatura ambientalista, associada ao paradigma "menos energia - menos complexidade", refere-se à crença de que, apesar de ser uma variável importante, um aumento na eficiência não seria a chave para a transição (Fernández \& González, 2014; Casal, 2016; Taibo, 2016). Quando se trata de aumentar a eficiência, apenas a tecnologia é mencionada, sempre adicionando uma crítica (que

4 "O Paradoxo de Jevons (ou efeito bumerangue - rebound effect) é uma expressão usada para descrever o fato de que o aperfeiçoamento tecnológico ao aumentar a eficiência com a qual se usa um recurso ou se produz um bem econômico, o mais provável é que aumente a demanda desse recurso ou produto. Este fenômeno foi observado pelo economista britânico William Stanley Jevons (1835-1882), que escreveu em 1865 o livro "O Problema do Carvão" (...)" [https://www.ecodebate.com.br/2012/02/29/o-paradoxo-de-jevons-e-a-questao-da-eficienciaartigo-de-jose-eustaquio-diniz-alves/] 
compartilhamos) ao otimismo tecnológico e à tecnocracia. O problema é que este enfoque é reducionista e simplificador, pois toma a eficiência apenas no campo tecnológico e não a relaciona à organização social em seu conjunto. Ao adotar a perspectiva que considera a organização social em seu conjunto, assim como defende Margalef (1974) e Morin (1986; 1987), tem-se a eficiência como um critério básico para avaliar as possíveis alternativas, segundo seu grau de resiliência.

Ao assumir essa perspectiva, que requer determinadas mudanças na organização social no sentido de aumentar sua eficiência energética, há uma adequação ao mundo de baixa energia. Isso significa inclusive, um aumento de complexidade do sistema. Vamos analisar isso detidamente. Comecemos por nossa "unidade organizacional básica". O que é mais complexa: uma organização social atomizada em famílias ou uma organização social de redes de comunidades coordenadas autossuficientes? Qual organização é mais resiliente do ponto de vista da eficiência energética? Pensemos por um momento sobre as economias de energia que vão dos usos domésticos atuais, centrados na unidade familiar (diversidade de eletrodomésticos, horas dedicadas em cada residência e os cuidados individualizados) a uma organização comunitária. Se atualmente consumimos cerca de $20 \%$ da energia produzida ao uso doméstico, quanta energia economizaríamos ao cozinhar para uma comunidade ao invés de família específica? Ou assumindo os cuidados coletivamente? Ou concentrando uma atividade comum nos períodos mais frescos no verão e as mais quentes do inverno?

Se, além disso, substituíssemos o desperdício de transporte horizontal por redes locais de produção e consumo, redes informatizadas de trabalho colaborativo e meios de transporte, que hoje consomem cerca de $40 \%$ da energia produzida no mundo, por aqueles mais ecológicos (coletivo, bicicletas e caminhadas), teríamos significativa economia de energia. Do mesmo modo, a instalação de empresas locais destinadas a produzir os bens básicos que são considerados essenciais reduziria consideravelmente o consumo de energia (considerando que cerca de $30 \%$ da produção de energia mundial é atualmente utilizada no setor secundário). Assim como uma reorganização radical do setor de serviços implicaria em uma economia considerável de energia.

Em relação a este último assunto, é necessário considerar o alto consumo de energia para manter e autoperpetuar o sistema capitalista através de mecanismos de controle da população, considerando a forma como estão organizados: as múltiplas burocracias administrativas existentes, o complexo militar-industrial assim como os diferentes sistemas jurídico e de segurança, o sistema financeiro e comercial, a mídia e entretenimento, e o próprio sistema educacional (pensemos nas horas de trabalho e nas calorias gastas por inúmeros alunos e alunas durante grande parte de suas vidas para se tronarem cidadãos e cidadãs obedientes e submissos). Esse tipo de organização social, baseada no antagonismo (competição, exploração, egoísmo e individualismo), não é apenas injusta, mas muito menos resiliente em termos de eficiência energética se comparada com uma organização pautada pela complementaridade (cooperação, 
simbiose, altruísmo, solidariedade etc.). Esse assunto é bastante claro na Biologia, especificamente no campo evolutivo: a complementaridade é o motor dos grandes avanços qualitativos, como são a passagem das células procarionte para a eucarionte ou do organismo unicelular para o organismo multicelular. Assim como na Ecologia, a complementaridade é a chave para a organização do ecossistema.

E a alimentação e o setor primário? Em parte da literatura ambientalista, a sociedade do futuro é descrita como uma sociedade menos urbana e mais rural, baseada um modelo agrícola mais simples, semelhante ao da agricultura pré-industrial. Diante disso, é possível constatar que estamos diante de um caso típico de descomplexificação e de "retorno ao passado". Será que existem outras opções? Os dados atuais sugerem que tanto a agricultura industrial quanto a pré-industrial tem menor eficiência energética (especialmente a industrial) quando comparada com a permacultura (Holmgren, 2013). A este respeito, considerando as "complexidades" em ambos os modelos, ao analisar as variáveis quantitativas, como a quantidade de energia requerida por um sistema e outro, a agricultura industrial apresenta maior consumo de energia frente a permacultura, uma vez que se baseia principalmente na contribuição de uma grande quantidade de energia exossomática presente nos combustíveis fósseis.

É evidente que um sistema de agricultura industrial é altamente eficaz visto o grande volume de alimentos produzido. No entanto, não é eficiente pois faz isso às custas de um elevado consumo de energia. Ou seja, usando outra variável quantitativa, como a taxa de Energia Retornada ${ }^{5}$ (em inglês, energy return), que se refere à relação entre as unidades de energia obtidas em relação às unidades investida, as taxas de agricultura industrial, próximas a 1, são muito menores que as de permacultura (mais de 20, de modo que com 1000 metros quadrados de terraços profundos e "floresta de alimentos" é possível alimentar quatro pessoas). Ou seja, a permacultura é muito mais eficiente no uso da energia e, portanto, é um modelo muito mais resiliente (Rodrígues-Marín, Fernández-Arroyo \& García, 2015).

Mas a comparação de ambos os modelos não termina aí. Ao analisar um sistema social que adota os princípios da permacultura (como modelo agrícola, como design territorial e como modelo de organização social) nota-se alta eficiência energética; economia de água e nutrientes; desenvolvimento de um solo vivo e complexo; alta biodiversidade; potencialização da complementaridade entre as espécies envolvidas na produção agrícola; aumento do desenvolvimento do transporte vertical de materiais frente ao horizontal; melhor ajuste dos ciclos biogeoquímicos e fluxo de energia; organização territorial em mosaico de forma a promover uma rede de ecossistemas interligados complementares; substituição da dieta carnívora pela vegetariana, eliminando um

5 EROEI, que é a sigla em inglês para "Energy return on Energy invested" (Energia Retornada sobre Energia Investida). Ou Eroi (Energy return on invested). O EROEI pode ser apresentado pela fórmula "K para 1", sendo $\mathrm{K}$ a quantidade de energia retornada por 1 unidade investida. Quanto mais alto for o EROEI mais eficiente é o combustível. Se K é próximo de 1, a fonte energética não é viável, pois utilizará tanto ou quanto na produção do que no seu retorno. 
passo na "pirâmide trófica humana" e, com isso, sendo possível consumir menos energia e diminuir emissões de metano, um dos gases de Efeito Estufa; e organização social baseada na complementaridade (cooperação, altruísmo, solidariedade etc.) em contrapartida ao antagonismo.

Uma organização social com essas características, baseada essencialmente em alta eficiência energética, complementaridade e respeito à biodiversidade, é claramente mais resiliente do que um modelo agrícola industrial, centrado na monocultura (redução radical da biodiversidade), transporte horizontal de materiais e o desperdício de recursos (desajustes em relação aos ciclos e fluxos naturais) e à destruição do ecossistema solo.

A partir dessa comparação, é possível identificar qual dos dois sistemas é mais complexo. Compartilhando a reflexão de Homer-Dixon (2006), que associa o colapso civilizatório à taxa de Energia Retornada, cabe pensar se a permacultura, que apresenta alta eficiência energética, não é uma alternativa básica "complexa" para diminuir as consequências negativas do decrescimento e até mesmo evitar o colapso. Este mesmo argumento pode ser transferido para o escopo de ideologias coletivas e sistemas de ideias.

\section{COMPLEXIFICAR PARA NÃO SIMPLIFICAR OS CONHECIMENTOS}

Podemos dizer que o processo de ensino-aprendizagem predominante tanto na Espanha quanto no Brasil, baseado em um sistema hierárquico e centralizador, regido por burocracias crescentes, acúmulo de informações de baixa qualidade, que promove a dependência e pensamento único, é mais complexo do que um sistema educacional pautado em um conhecimento organizado, que busca a autonomia, criatividade, diversidade, versatilidade e criticidade, tal como defendem Morin (2001) e Freire (1977)? O que contribui para perpetuar o sistema capitalista: um pensamento simplificador, reducionista, mecanicista e mítico ou um baseado na adoção de diferentes perspectivas, na concepção sistêmica do mundo, na causalidade entendida como a interação e na capacitação da cidadania para resolver problemas?

Ao considerar a lei dos rendimentos decrescentes é fundamental evitar o seu uso universal, especificamente, sua aplicação desconsiderando o âmbito do conhecimento. As ideias de Tainter (1996) acerca de uma ciência e tecnologia cada vez mais complexas, que acabam por prejudicar mais recursos do que sua capacidade de regeneração, poderia ser aplicada à atual burocracia científico-tecnológica (direcionada à autoperpetuação do sistema capitalista e não para o bem comum), mas não à ciência como forma de conhecimento. Como já foi indicado, uma complexificação progressiva 
dos sistemas de ideias tem um efeito multiplicador e jamais de subtração (Morin, 1992, 2001). Isso ocorre porque uma sociedade comprometida com uma complexidade do conhecimento terá muitas mais opções de sobrevivência do que uma que retorna a posições culturais "mais simples" (neoarcaica).

No caso do conhecimento, a associação entre o crescimento (mais salas de aula, mais pessoas na escola, mais aparatos burocráticos, mais recursos) e complexidade é muito discutível. A psicologia da educação atual mostra-nos que a quantidade não é a variável determinante, mas a maneira como a informação está organizada. Nesse sentido, a qualidade nos dá uma melhor medida de complexidade (Morin, 1988, 1992 e 2001). A mente de uma pessoa pode reter muitos dados, mas se esses dados não estão integrados em um sistema de ideias bem organizado eles não servem para resolver problemas e, portanto, temos menos resiliência.

No entanto, muitas vezes encontramos na literatura ambientalista e nas pesquisas em educação e ensino, a associação quantidade-complexidade aplicada ao tema do conhecimento. Um exemplo paradigmático desta abordagem aparece no texto por Fernández e González (2014) ao tratar como uma crescente complexidade social o aumento de estudantes universitários. Do ponto de vista que defendemos, uma maior complexidade estaria em conseguir mentes bem ordenadas no sentido de Morin (2001) e organizadas a ponto de se entender o mundo que nos cerca, no sentido de Freire (1977). O aumento da complexidade, em última análise, exige muito menos energia do que a produção de titulados repletos de informações de "baixa qualidade". Um sistema de ideias altamente organizado internamente seria mais complexo (e mais resiliente e econômico do ponto de vista da energia) do que um sistema com muitos conhecimentos, atomizado, compartimentado e vinculado à submissão da população (García, 2004a; 2004b; Freire, 1977). Sobre isso, cabe salientar que a busca por um sistema dessa natureza não se promove apenas por ações pontuais; demanda uma mudança de paradigma que vai levar a sua incorporação tanto no contexto da educação, quanto do ensino-aprendizagem e da própria epistemologia da ciência (Watanabe \& Kawamura, 2014).

Em suma, a discussão sobre um sistema sustentável de resolução de problemas (Tainter, 1996) não pode se concentrar estritamente na questão econômica, voltada aos custos, mas também no tema organizacional. Nesse sentido, educar toda uma população pautando-se na complexificação do conhecimento e no desenvolvimento de uma atitude investigativa criativa e crítica, representaria um salto qualitativo na resolução de problemas para uma sociedade que não se baseia na dominação. A atitude investigativa criativa e crítica aqui destacada se aproxima das ideias de Freire (1977), em especial, ao considerar os papéis assumidos pelos(as) docentes e estudantes no processo de ensino-aprendizagem. De forma mais ampla, a criticidade implica numa libertação social, na promoção da capacidade de tomar decisões políticas frente às situações reais e complexas. Ela demanda o entendimento sobre o mundo e requer, para isso, nos tornarmos construtores de nossas culturas. Nesse sentido, Freire (2017) salienta que 
Quando o homem e a mulher se percebem como fazedores de cultura, quando apreendem o conceito antropológico de cultura, está vencido, ou quase vencido, o primeiro passo para sentirem a importância, a necessidade e a possibilidade de se apropriarem, criticamente, da leitura e da escrita da palavra. Estão alfabetizando-se, politicamente falando. (Freire, 2017, p.291)

Ainda no contexto do conhecimento, e considerando as produções de natureza socioambiental incluindo as da área de educação e ensino, é possível identificar uma certa mitificação do conhecimento próprios dos saberes tradicional e do senso comum. Em outras palavras, se superestima a simplificação promovendo a recuperação e/ou uso de outras formas de conhecimento que, em muitos casos, referem-se ao conhecimento mítico. Do ponto de vista da resiliência e da eficiência energética, o debate de fundo é o papel dado às diferentes formas de conhecimento em uma sociedade "pós-colapso". A este respeito, aparece com frequência a ideia de que a ciência e a tecnologia são irrelevantes em uma sociedade descomplexificada. Independentemente da perspectiva de ciência ${ }^{6}$ de que estamos tratando, a questão é: outras formas de conhecimento, tais como o conhecimento mítico e o cotidiano, nos asseguram uma melhor adaptação em uma situação de decrescimento?

Do nosso ponto de vista, é essencial recuperar o pensamento científico e o conhecimento organizado como um instrumento para resolver os problemas contemporâneos. Implica em recuperá-los para toda a população, promovendo uma educação escolar científica de qualidade. Há, portanto, de se começar do zero e reinventar o que já é conhecido, excluindo as abordagens que não nos ajudam sobreviver na medida em que promove o desperdício de horas de trabalho e energia. Já sabemos, por exemplo, que se economiza muito mais energia retirando um balde de água de um poço com uma manivela, um guincho e uma polia, do que puxando-o com uma corda. Por que buscar esse conhecimento novamente por tentativa e erro? Também sabemos quais plantas de cultivo são complementares às outras ou quais espécies são mais resistentes às pragas. Nesse sentido, será que devemos colocar a segurança alimentar da população em risco tentando novamente redescobrir o que já foi descoberto?

Obviamente, não nos vale qualquer ciência ou qualquer tecnologia. A aposta é por uma ciência e uma tecnologia que respeite ao menos os princípios básicos, a saber: busca por uma maior eficiência energética associada ao uso de energias renováveis; ajuste aos ciclos de materiais (por exemplo, privilegiando o transporte vertical-local sobre o horizontal e buscando promover pelo fechamento desses ciclos); e ajuste aos ritmos do planeta (Mediavilla, 2016).

Além disso, é importante nos aproximar dos problemas socioambientais da mesma maneira que a ciência, ao desenvolver um ideário coletivo mais "complexo", baseado

6 Não é o mesmo falar sobre a perspectiva da Ciência mecanicista do século XIX e das perspectivas da Ciência relativista, indeterminista e complexa, do século XX. 
na investigação de problemas, na criatividade, no pensamento crítico e complexo, no conhecimento científico e trabalho cooperativo. Com isso é possível aumentar nossa capacidade de resiliência (e a complexidade do sistema). Em particular, propomos, no âmbito de uma aproximação da perspectiva da complexidade, uma revalorização do papel da ciência e da tecnologia adaptadas a uma sociedade em decrescimento, uma vez que dar preeminência ao conhecimento cotidiano e as ideias míticas supõe reduzir a resiliência da população no momento em que tem que enfrentar problemas como a mudanças climáticas ou o possível esgotamento de recursos naturais.

\section{EDUCAR CRITICAMENTE PARA O DECRESCIMENTO}

Como já anunciado, é com certa frequência que identificamos nos discursos socioambientais a ideia recorrente de que devemos conscientizar e educar a população para que ela reaja aos desafios que enfrentaremos devido aos limites biofísicos. A este respeito, e considerando os argumentos trazidos neste ensaio, seria fundamental contar com um programa de ação considere dois elementos básicos.

O primeiro deles implica em promover um debate acerca da pertinência do conceito de sustentabilidade tomando como referência os movimentos de transição, sobretudo porque é uma noção onipresente em todos os processos educacionais e de conscientização dos cidadãos e das cidadãs. Nessa perspectiva, a questão que se coloca refere-se à qual a potencialidade real do conceito como agente transformador do sistema. É verdade que a noção de sustentabilidade teve sucesso significativo em seu discurso tanto nos movimentos institucionais quanto nos sociais. No entanto, obteve pouco sucesso como instrumento de mudança social de modo que, desde seu surgimento na década de 1980, (i) o modelo de crescimento ilimitado quase não se alterou (basta, para isso, verificar que o aumento do PIB continua a ser o paradigma dominante); (ii) o desperdício de recursos é crescente, contrariando a ideia de poupança sustentável; (iii) os resíduos contaminantes aumentaram, contribuindo possivelmente para as mudanças climáticas e a inação institucional diante deste fato; e (iv) as desigualdades amplificaram (neste aspecto é onde estamos cada vez mais distantes das propostas de sustentabilidade em relação a satisfazer as necessidades de toda a população).

Por que se teve tão pouco resultado prático? São evidentes as dificuldades em mudar o sistema, mas acreditamos que a noção de sustentabilidade tem pecado pela ambiguidade, uma vez que a ideia de desenvolvimento sustentável se encaixa em quase tudo. Ao não se pronunciar claramente por mudanças nas regras do jogo, ou seja, ao propor uma reforma sem questionar a organização política e socioeconômica dominante, se expos a fragilidade da proposta. É mais fácil, e politicamente "mais 
correto", identificar o significado da mudança com "ir para o desenvolvimento sustentável" ou "melhorar o mundo no capitalismo", do que dizer, por exemplo, que o capitalismo deve acabar sem mais detalhes. Um primeiro ponto fraco do modelo estaria, então, em sua dimensão política.

Além disso, não devemos esquecer o contexto histórico em que o conceito se origina: é uma concessão do capitalismo "bondoso" (o estado de bem-estar dos anos 60 e 70) aos movimentos sociais justos antes do triunfo avassalador do neoliberalismo e do capitalismo da acumulação por desapropriação (desde a década de 80 até agora). Esta mudança para um capitalismo selvagem, típico do neoliberalismo e da globalização econômica, deixa o modelo de desenvolvimento sustentável sem margem de manobra. É claro que com essas novas orientações fica muito complicado reformar o sistema (a este respeito, é visível a incapacidade de apontar alternativas sociodemocráticas que associamos, em grande parte, a ideia de sustentabilidade para contrastar as teses neoliberais). São orientações em que não faz sentido falar sobre "sustentar" o nosso modo de vida atual em um contexto de mudanças climáticas, esgotamento do combustível fóssil e acúmulo de recursos limitados pelas classes dominantes (ainda que com violência crescente) e sem qualquer interesse redistributivo.

De fato, o discurso da sustentabilidade, ao ignorar o decrescimento e o colapso muito provável do sistema capitalista, pode servir para ocultar a dura realidade em que estamos, oferecendo uma falsa esperança à população sobre a possibilidade de reformar o sistema. Neste contexto, pensamos que a educação para o desenvolvimento sustentável não deve ser considerada como uma educação para o decrescimento, ou seja, há de se pensar em educar as pessoas para se adaptem a um mundo com menos recursos, de forma que essa adaptação não seja caótica, mas ordenada e justa. Adaptação que supõe dar prioridade, acima de tudo, à construção de modelos de organização social que otimizem o uso de recursos cada vez mais escassos, na perspectiva de considerar o decrescimento não como um "retorno ao passado", mas como uma oportunidade de mudança social para uma sociedade melhor (Latouche, 2012). Neste contexto, a conscientização e a educação dos cidadãos e cidadãs não podem se limitar apenas à organização de campanhas de persuasão. Parece importante educar as pessoas em ação, criando redes que imbricam o sistema educacional com as lutas dos movimentos sociais e com as experiências locais típicas dos movimentos de transição, tal como já apontava Freire (1977).

Em segundo elemento básico refere-se à mudança de ideologia coletiva, ou seja, a superação das barreiras mentais que os sistemas de controle social criaram na maioria da população. Parece clara que qualquer intervenção educacional deve estar em conformidade com as características dos e das aprendizes. Portanto, é imprescindível conhecer bem quais barreiras ou obstáculos presentes no conhecimento cotidiano podem dificultar uma mudança na mentalidade da população em relação à sua melhor adaptação a uma situação de decrescimento. Claramente, temos uma população 
socializada na ideologia neoliberal, uma população alienada que desconhece os riscos associados ao choque de nossa civilização industrial com os limites biofísicos, que mitificam a inovação tecnológica (que nos salvará), que rejeita os argumentos que provocam agitação e incerteza, ou que resignadamente aceita um destino que considera inevitável (fatalismo, conformismo). É, por isso, conveniente analisar esses obstáculos e procurar as estratégias mais apropriadas para superá-los.

Dois obstáculos fundamentais para a mudança referem-se à negação e ao conformismo. A este respeito, existem dois mecanismos psicológicos que influenciam, a saber: (i) ao comparar e avaliar dois argumentos distintos tendemos a aceitar aquele que gera menos desconforto (dissonância cognitiva), especialmente se os argumentos tranquilizadores forem mais abundantes e repetitivos (veiculados por meio de propagandas), embora sejam menos racionais; e (ii) ao comprovar a partir de nossa experiência cotidiana que nas escolhas realizadas sempre há perdas e pouco controle da situação (o que na psicologia se denomina desamparo aprendido) nos tornamos fatalistas, conformistas e desconfiamos da nossa capacidade de controlar o mundo. Para superar essas barreiras é preciso evitar um discurso baseado nas ideias catastróficas ou regressivas. Precisamente, o medo pode servir tanto para provocar uma reação (e compreender um risco que não foi visto como imediato) como, no caso da dissonância cognitiva, para trazer à tona argumentos mais reconfortantes (por exemplo, utilizar discurso de que algo não é verdade visto o ponto de vista catastrófico ou se apoiar nas novas tecnologias para resolver os problemas). Neste caso, as questões emocionais jogam contra nós, sendo necessário então apelar para a razão, fornecendo dados rigorosos que ajudam na compreensão dos aspectos que levam ao decrescimento e, acima de tudo, argumentos que promovam segurança, tranquilidade e confiança em nossa capacidade de mudar o mundo. Tais argumentos devem estar baseados na ideia de que a variável principal não é o limite biofísico, mas a resposta social a esse limite, de modo que com a adoção de modalidades de organização social (redes comunitárias coordenadas autonomamente e autossuficientes; permacultura; complementaridade em vez de antagonismo etc.) mais eficientes é viável viver melhor e com menos (entender o decrescimento como uma oportunidade de melhoria).

E nesta luta para racionalizar e complexificar a nossa percepção dos problemas do mundo é fundamental a revalorização da Ciência. Como já destacamos, não podemos renunciar a um conhecimento organizado que a humanidade vem construindo ao longo do tempo e que é um instrumento essencial para resolver problemas. Obviamente, rejeitamos a instrumentalização da Ciência pelo capitalismo e acreditamos que devemos complementar as contribuições da Ciência com as de outras formas de conhecimento. Mas dado que não estamos em um debate em uma sala de aula, mas diante de uma questão de sobrevivência, qualquer hipótese, qualquer proposta de ação, deverá ser submetida a uma avaliação crítica, à negociação das "verdades" argumentadas com evidências empíricas, sem assumir dogmaticamente determinados postulados que possam supor a nossa extinção. 


\section{REFERÊNCIAS BIBLIOGRÁFICAS}

Brasil. (1999). Dispõe sobre Educação Ambiental e institui a Política Nacional de Educação Ambiental. Lei 9.795, de 27.04.1999. Brasília: DOU.

Brasil. (2000). Parâmetros Curriculares Nacionais: Ciências da Natureza, Matemática e suas Tecnologias. Ministério da Educação. Brasília: MEC.

Brasil. (2002). PCN+ Ensino Médio: Orientações educacionais complementares aos Parâmetros Curriculares Nacionais. Ciências da Natureza, Matemática e suas Tecnologias. Ministério da Educação. Brasília: MEC.

CARVALHO, F. R., WATANABE, G.,\& Rodriguez-Marin, F. (2017). Construção do conhecimento escolar científico na perspectiva da complexidade. Enseñanza de las Ciencias, v. extra, $3237-3242$.

CARVALHO, F. R, \& WATANABE, G. (2016). Uma proposta para identificar elementos da complexidade nos argumentos dos alunos. Encontro de Pesquisa em Ensino de Física.

CASAL, L. M. (2016). La izquierda ante el colapso de la civilización industrial. Madrid: La Oveja Roja.

DELEAGE, J. P. (1993). Historia de la ecología. La ciencia del hombre y de la naturaleza. Barcelona: Icaria

FELBER, C. (2015). La economía del bien común. Barcelona: Deusto.

FERNÁNDEZ, R.; GONZÁLEZ, L. (2014). En la espiral de la energía. Madrid: Libros en Acción. Baladre.

FREIRE, A.M.A. (2017). Paulo Freire: uma história de vida. Rio de Janeiro: Paz e Terra. FREIRE, P. (1977). Pedagogia do oprimido. Rio de Janeiro: Paz e Terra.

GARCÍA, E. (2004a). Educación Ambiental, Constructivismo y Complejidad: una propuesta integradora. Sevilla: Díada.

GARCÍA, E. (2004b). Los contenidos de la educación ambiental: una reflexión desde la perspectiva de la complejidad. Investigación en la Escuela, 53, 31-52.

GOLLEY, F. B. (1993). A History of the Ecosystem Concept in Ecology: More than the Sum of the Parts. New Haven and London: Yale University Press. 
HOLMGREN, D. (2013). Permacultura: principios y senderos más allá de la sustentabilidad. Argentina: Kaicron.

HOMER-DIXON, T. (2006). The upside of down: catastrophe, creativity and thereneval of civilization. Toronto: Alfered A Knopf, Canada/ Random House of Canada Limited.

LATOUCHE, S. (2007). Sobrevivir al desarrollo. Barcelona: Icaria Editorial.

LATOUCHE, S. (2009). Pequeño tratado del decrecimiento sereno. Barcelona: Icaria Editorial.

LATOUCHE, S. (2012). La sociedad de la abundancia frugal. Barcelona: Icaria Editorial.

LEVINS, R. \&LEWONTIN, R. (1980). Dialectics and reductionism in ecology. Synthèse, 43, 47-78.

MARGALEF, R. (1974). Ecología. Barcelona: Omega.

MARGALEF, R. (1980). La biosfera, entre la termodinámica y el juego. Barcelona: Omega.

McINTOSH, R.P. (1985). The background of ecology. Cambridge: Cambridge University Press.

MEDIAVILLA, M. (2016). La tecnología que nos va a salvar, la tecnología que nos puede transformar. In: Prats, S., Herrero, Y. \&Torrego, A. La Gran Encrucijada. Barcelona: Libros en Acción /Icaria.

MORIN, E. (1986). El Método I: La Naturaleza de la Naturaleza. Madrid: Cátedra.

MORIN, E. (1987). El Método II: La Vida De la Vida. Madrid: Cátedra.

MORIN, E. (1988). El Método III: El Conocimiento del Conocimiento. Madrid: Cátedra.

MORIN, E. (1992). El Método IV: las ideas. Su hábitat, su vida, sus costumbres, su organización. Madrid: Cátedra.

MORIN, E. (1994). Introducción al Pensamiento Complejo. Barcelona: Gedisa.

MORIN, E. (2001). La mente bien ordenada. Repensar la reforma. Reformar el pensamiento. Barcelona: Seix Barral.

PRATS, S., HERRERO, Y., \& TORREGO, A. (2016). La Gran Encrucijada. Barcelona: Libros en Acción /Icaria.

PRIGOGINE, I. O nascimento do tempo. Rio de Janeiro: Edições 70, 1988. 
PRIGOGINE, I. (1993). Enciclopédia Einaudi: Sistema. Portugal: Imprensa Nacional, Casa da moeda.

PRIGOGINE, I. (1996). O fim das certezas: tempo, caos e as leis da natureza. São Paulo: Editora da UNESP.

PRIGOGINE, I. (2002). As leis do caos. São Paulo: Editora UNESP.

PRIGOGINE, I. (2009). Ciência, razão e paixão. São Paulo: Livraria da Física.

PRIGOGINE, I., \& STENGERS, I. (1984) A nova aliança. Brasília: Editora Universidade de Brasília.

PRIGOGINE, I., \& STENGERS, I. (1992) Entre o tempo e a eternidade. São Paulo: Companhia das letras.

PUIG-GUTIÉRREZ, M. et. al. (2017). Ciudadanía, Sostenibilidad Y Patrimonio: Un Análisis Curricular. In XXVIII Simposio Internacional de didáctica de las ciencias sociales. Córdoba 4-6 de abril de 2017. Disponível em: <http://dialnet.unirioja.es/ servlet/articulo?codigo=6131946>. Acesso em: 14 fev. 2018.

RIECHMANN, J. (2016) ¿Derrotó el smartphone al movimiento ecologista? Para una crítica del mesianismo tecnológico. Madrid: Los Libros de la Catarata.

RODRÍGUEZ-MARÍN, F., FERNÁNDEZ-ARROYO, J., \& GARCÍA, E. (2015). El huerto escolar ecológico como herramienta para la educación en y para el decrecimiento. Investigación en la Escuela, 86, 35-48.

TAIBO, C. (2016). El colapso. Madrid: Los Libros de la Catarata.

TAINTER, J. A. (1996). Complexity, problem solving and sustainable societies. In Getting down to earth: practical applications of ecological economics, Island Press. Disponível em: http://www.dieoff.com/page134.htm.

TURIEL, A. (2011). Por qué se despilfarra tanto. Disponível em: http://crashoil. blogspot.com.es/2011/09/por-que-se-despilfarra-tanto.html

TURIEL, A. (2016). El temor al colapso. Disponível em: http://crashoil.blogspot.com. es/2016/07/el-temor-al-colapso.html

TURIEL, A. (2017). De hormigas y hombres. Disponível em: http://crashoil.blogspot. com.es/2017/05/de-hormigas-y-hombres.html

WATANABE, G. (2012) Aspectos da complexidade: contribuições da Física para a compreensão do tema ambiental. (Tese de Doutorado em Ensino de Ciências). Instituto de Física e Faculdade de Educação, Universidade de São Paulo, São Paulo. 
WATANABE, G., \& KAWAMURA, M.R.D. (2017) Abordagem temática e conhecimento escolar científico complexo: organizações temática e conceitual para proposição de percursos abertos. Investigações em ensino de ciências, 22, 145 $-161$.

WATANABE, G, \& KAWAMURA, M. R. (2014). Uma educação na perspectiva ambiental crítica, complexa e reflexiva. Revista Brasileira de Pesquisa em Educação em Ciências. 14 (2), 255-264.

WATANABE, G., \& RODRÍGUEZ-MARÍN, F. (no prelo). Aspectos da complexidade nas questões socioambientais: as abordagens no Brasil e na Espanha. Revista Ciência \& Educação. Bauru: UNESP.

José Eduardo García Díaz é professor doutor do departamento de Didáctica de las Ciencias Experimentales y Sociales da Universidad de Sevilla, Espanha. Atua na rede IRES (Investigación y Renovación Escolar) e na Asociación MontequintoEcológico-Ecologistas en Acción. No grupo de investigação Didactica e Investigacion Escolar estuda estratégias de desenvolvimento profissional de professores em relação à experimentação curricular. É autor de diversos livros sobre a complexidade no contexto escolar.

Giselle Watanabe é professora doutora do Centro de Ciências Naturais e Humanas da Universidade Federal do ABC, Brasil. É pós doutora pela Universidad de Sevilla. Tem experiência na área de Ensino de Ciências, atuando principalmente nos assuntos complexidade, meio ambiente e criticidade voltados ao currículo de Ciências e Ensino de Física. Lidera o grupo de pesquisa GrECC, que estuda aspectos da complexidade e criticidade no contexto escolar. 